\title{
Psychiatry in a postgraduate teaching hospital
}

\author{
DaVid AbRahamson* \\ M.B., D.P.M., M.R.C.P.I \\ Department of Psychiatry, Hammersmith Hospital, London, W.12
}

\begin{abstract}
Summary
A study is presented of $\mathbf{2 1 7}$ adults referred for psychiatric assessment from the wards of a postgraduate teaching hospital.

The pattern of referral and the disproportionate importance of disturbed behaviour amongst referrals from non-medical wards are discussed. The main diagnostic groups, namely, affective disorders, organic states, psychogenic somatic symptoms and attempted suicide, are tabulated and discussed. Complex problems of diagnosis and management were common and are considered under five headings: multiple pathology; the effects of intensive treatment procedures; language and cultural differences, and difficulties in follow-up.

It is concluded that the problems met in this specialized setting are likely to become general as intensive treatment and diagnostic procedures become more widespread.

The importance of organic reactions is stressed and their relative neglect by both psychiatrists and physicians commented on. The frequency of social precipitants of affective disorders and attempted suicide, however, is considered to emphasize the range of activities required of the psychiatrist in even the most technologically advanced centres.
\end{abstract}

\section{Introduction}

The integration of psychiatry into the general hospital services is an important contemporary trend. Lipowski (1967a) has called it 'one of the most significant developments in American psychiatry since World War II', and it is part of official policy for the development of the National Health Service in England and Wales (Department of Health, 1970).

Concomitantly with this trend there has grown up a considerable literature on general hospital psychiatry. This ranges over consultation and 'liaison' services (Fleminger \& Mallett, 1962; Kenyon \& Rutter, 1963; Eilenberg, 1965; Kornfeld \& Feldman, 1965; Engel, 1967; Crisp, 1968), the treatment of patients with formal psychiatric illness within general medical wards (Brook \& Stafford-Clark, 1961) and comprehensive general hospital psychiatric units (Silverman, 1968; Hoenig \& Hamilton, 1969; Watson, Bennett \& Isaacs, 1970).

\footnotetext{
* Present address: Goodmayes Hospital, Barley Lane, Ilford, Essex.
}

The present study deals with a consultation service which had certain unusual features that underline the need for data from a wide variety of sources of different types, if generalizations about the tasks of the general hospital psychiatrist are to be valid.

\section{Material}

This study deals with 217 adult patients referred for psychiatric consultation from the wards of the Hammersmith Hospital during the period from 1 July 1968, to 31 October 1969. The patients were all seen personally by the author and comprised $82 \%$ of all adult ward referrals during this period.

The hospital has 578 beds (excluding paediatric and staff beds) of which 240 are medical, 193 surgical and 145 for obstetrics and gynaecology. It is a postgraduate teaching institution, unusual in the technological facilities and expertise available and with a particular emphasis on the growing points of medicine. For this reason patients are frequently referred from far afield.

\section{Results}

\section{Sources of referral}

The majority of patients $(81 \%)$ were referred from the medical wards, with a much lower rate of referral from the surgical $(12 \%)$ and obstetrics and gynaecology $(7 \%)$ departments. This discrepancy remains large even if suicide attempts, the great majority of which are admitted to medical wards, are excluded. Other studies have shown similar results (Fleminger \& Mallett, 1962; Kenyon \& Rutter, 1963; Eilenberg, 1965).

The referral rates for non-medical patients are most unlikely to reflect the true incidence of psychiatric disorder amongst these patients (Zwerling et al., 1955; Hockaday, 1961; Baird, 1969). Even medical referrals are probably an underestimate of the frequency of psychiatric disturbances (Helsborg, 1958; Culpan \& Davis, 1960; Denney, Quass \& Rich, 1966; Richman, Slade \& Gordon, 1966).

\section{Reasons for referral}

It seems likely that the low rate of referral of patients from the surgical and to a lesser extent the 
obstetrics and gynaecology wards reflects lack of awareness of psychiatric disorders that do not interfere with routine management. This interpretation is supported by the finding that difficult or disturbing behaviour was responsible for $38 \%$ of the surgical referrals, $18.5 \%$ of referrals from the obstetrics and gynaecology unit, and only $6 \%$ of medical referrals.

\section{Diagnoses}

The final diagnoses are listed in Table 1.

\section{Affective disorders}

Affective disorder was the most common diagnosis, apart from the group of attempted suicides which are considered separately. The term was used to cover all depressive illnesses together with the much fewer pure anxiety states. Other than those in this group, no neurotic disorders were diagnosed, apart from the hysterical symptoms which are tabulated below under the heading of psychogenic somatic symptoms. It was possible to divide the major precipitants of the affective disorders roughly into five groups, which are detailed in Table 2. The two most important groups were 'social', e.g. bereavement, marital problems and loneliness, and 'illness', the effects of severe physical illness and disability, and of operations and similar procedures.

In the 'social' group it appeared that in many cases the physical symptoms present would not have led to admission except for the patient's active and persistent seeking of treatment, in response to psychological distress. This response has been investigated elsewhere (Mechanic \& Volkart, 1961) and such distress has also been shown to affect the outcome of medical treatment (Querido, 1959).

TABle 1. Diagnoses

\begin{tabular}{lrr}
\hline Diagnosis & No. & $\%$ \\
\hline Affective disorder & 59 & 27 \\
Attempted suicide & 79 & 36 \\
Organic reaction & 36 & 17 \\
Psychosomatic disorder & 20 & 9 \\
Personality disorder & 7 & 3 \\
Schizophrenia & 4 & 2 \\
No psychiatric disorder & 6 & 3 \\
Uncertain & 6 & 3 \\
$\quad$ Total & 217 & 100 \\
\hline
\end{tabular}

TABle 2. Precipitating factors in affective disorders

\begin{tabular}{lrr}
\hline Precipitating factor & No. & $\%$ \\
\hline Illness and operations & 29 & 49 \\
Social & 19 & 32 \\
Puerperal & 9 & 16 \\
Nil & 2 & 3 \\
$\quad$ Total & 59 & 100 \\
\hline
\end{tabular}

In the 'illness' group, problems of management were prominent, particularly those of drug toxicity and interaction (Shepherd, Lader \& Rodnight, 1968; Alexander \& Nino, 1969; Prescott, 1969).

For this and other reasons explanation and $\stackrel{\vec{F}}{\rightarrow}$ reassurance was frequently more important than 을 medication in these cases, especially when physical illness or the effects of operation could be expected to remit or be relieved. In some instances, however, relief was not possible until the depressive symptoms on were first effectively dealt with. It is also noteworthy that depression secondary to physical disability may respond to antidepressants even when the disability cannot be relieved (Mindham, 1970).

\section{Organic disorders}

An important feature of the material is the considerable incidence of organic disorders: $15.5 \%$ of in the entire material; more realistically, if suicide $\stackrel{\sigma}{-}$ attempts are excluded, $23 \%$. This is considerably of higher than the percentage in most other general hospital studies (Fleminger \& Mallett, 1962; Kenyon 은 \& Rutter, Eilenberg, 1965; Kornfeld \& Feldman, 1965).

The organic disorders diagnosed are further detailed in Table 3.

The six patients with dementia were referred primarily for advice about disposal. Investigationg did not identify any of the remediable conditions known to cause dementia (Roth \& Myers, 1969).

Two of the cases of cerebral tumour diagnosed are discussed later. The third patient was admitted because of a suicide attempt. An organic pattern of headaches led to investigation and the detection of a pituitary adenoma.

The confusional states are further discussed below.

\section{Psychosomatic disorders}

The classical psychosomatic disorders were rarely referred. This is a general finding: Lipowski (1967b) found that of 808 referrals reported in the American literature only $6 \%$ were so diagnosed.

However, twenty-two patients were referred because of somatic symptoms suspected of being psychogenically determined. A variety of symptoms

TABle 3. Organic disorders

\begin{tabular}{lrr}
\hline Diagnosis & No. & $\%$ \\
\hline Dementia & 13 & 36 \\
Confusional states & 10 & 28 \\
Cerebral tumours & 3 & 8 \\
Epilepsy & 3 & 8 \\
Vitamin deficiencies & 2 & 6 \\
Myxoedema & 1 & 3 \\
Other & 4 & 11 \\
$\quad$ Total & 36 & 100 \\
\hline
\end{tabular}


were concerned: abdominal pain, 'fits and faints' and chest pain being most frequent. However, the pattern of presenting symptoms owed a good deal to the interests of particular physicians. In eight of these patients the symptoms were thought to be organic; in a further eight the final diagnosis was depression; in three, hysterical reactions were diagnosed. One patient was schizophrenic and two remained undiagnosed. These figures, however, do not fully convey the difficulties encountered and the frequently tentative nature of the conclusions reached.

\section{Complex problems}

Diagnosis and management of this material posed considerable problems, and the need for close and continuing liaison between physician or surgeon and psychiatrist was clear. The causes of these problems included: (1) the commonness of complex and multiple pathology, (2) the concentration of intensive surgical and other treatment and investigation facilities, (3) language and cultural differences, and (4) the difficulty of following up patients referred from afar.

(1) The problems posed by multiple pathology are illustrated by the histories of three patients.

Case 1. H. H., aged 63, underwent a Polya gastectomy for a duodenal ulcer in 1949. In 1956, she was diagnosed elsewhere as a 'chronic hysteric with severe hypochondriasis' and was thought to be addicted to barbiturates. Between 1961 and 1967 she was referred on a number of occasions, because of multiple fractures of ribs and long bones. These were at first thought to be due to falls consequent on alcohol and barbiturate consumption. However, in 1967 , she developed widespread bone pain, and was found to have marrow changes suggestive of multiple myeloma.

When admitted on the present occasion she had a 6-month history of frontal headaches, with a possible increase in her habitual aggressiveness and irritability, and a 6-week history of incontinence of urine and faeces, to which she was indifferent. Megaloblastic anaemia due to malabsorption of vitamin $B_{12}$ was present.

There were no neurological signs and no gross intellectual deterioration.

However, arteriography suggested the presence of a bifrontal meningioma, which was confirmed at craniotomy and successfully removed.

In this complex case a single symptom, incontinence, was of paramount importance in leading to the diagnosis. Hunter, Blackwood \& Bull (1969) have recently reviewed frontal meningioma presenting psychiatrically and point out the importance of this symptom, drawing on its analysis by Andrew \& Nathan (1964). In the present case it is only possible to speculate on the relationship of the tumour to the earlier history, although clearly it must have been present for some years.

Case 2. Mrs V. M., aged 64, was admitted because of intense agitation, which had resulted in 'collapse' without apparent loss of consciousness. Her agitation appeared to be due to the strain of caring for a paralysed and incontinent husband. Her inability to give an adequate history even after rest and sedation raised doubts about her cognitive function however, and gross intellectual impairment was confirmed by psychological testing. Further investigations revealed the presence of both a craniopharyngioma and pernicious anaemia. Surgical opinion suggested that the tumour was not responsible for her symptoms, although presentation of this tumour as a confusional state in the elderly is well documented (Ross Russell \& Pennybacker, 1962), and the pernicious anaemia appeared to be the significant pathology.

Treatment of this produced considerable improvement both in her ability to manage her daily life and in psychological test results.

Psychiatric disturbance due to pernicious anaemia is well recognized and it has been suggested that vitamin $\mathrm{B}_{12}$ deficiency in the absence of anaemia may also cause such disturbance, particularly in the form of confusional states and dementia (Holmes, 1956; Smith, 1960; Strachan \& Henderson, 1965). That it may be coincidental, however, is illustrated by the first case, and by other reports in the literature (Shulman, 1967).

Case 3. Mrs H. W., aged 48, was admitted because of the development of leucopenia during gold therapy for severe rheumatoid arthritis. It was then discovered that she had recently been displaying florid paranoid symptoms. She was already known to the psychiatric department and to other psychiatric agencies because of a long-standing personality disorder and depressive and anxiety symptoms, but it was clear that she had never before shown paranoid delusions. This, together with a slightly myxoedematous appearance, led to further clinical appraisal and investigations which confirmed the presence of hypothyroidism due to autoimmune thyroiditis (Hashimoto's disease).

(2) The importance of major surgery as a cause of psychiatric disturbance is being increasingly discussed (Kemph, 1969). The author has surveyed the psychiatric complications of open-heart surgery independently of the referred material and has confirmed that such complications frequently go unrecognized (Abrahamson, 1971). Diagnosis of such patients, often critically ill, nursed under intensive care conditions and unfit for exhaustive examinations, may be difficult, especially when language differences are present. The differentiation of episodes of confusion from functional disturbances may in some cases only be possible in retrospect, by 
TABLE 4. Factors in attempted suicide

\begin{tabular}{lrrrrr}
\hline \multicolumn{1}{c}{ Primary diagnosis } & \multicolumn{5}{c}{ Additional factors* } \\
& No. & $\%$ & $\begin{array}{c}\text { Personality } \\
\text { disorder }\end{array}$ & Depression & $\begin{array}{c}\text { Social } \\
\text { Crisis }\end{array}$ \\
\hline Personality disorder & 28 & 35 & - & 46 & 61 \\
Depression & 28 & 35 & 18 & - & 35 \\
Alcoholism and drug dependence & 8 & 10 & 87 & 12 & 12 \\
Schizophrenia & 3 & 4 & & 100 & -13 \\
Organic disorder & 1 & 1 & - & - & 100 \\
No psychiatric disorder & 11 & 14 & - & & \\
$\quad$ Total & 79 & 99 & & & \\
\hline
\end{tabular}

* Percentages of primary diagnosis.

the manner of recovery and the description then obtainable.

Amongst intensive medical procedures peritoneal dialysis was the most common cause of organic psychiatric complications. Tyler (1968) has commented on the considerable incidence of confusional states during this procedure-acute neurological complications being more characteristic of haemodialysis. A number of causes of dialysis complications are recognized, including abnormalities of urea balance (Kennedy, Linton \& Eaton, 1962; Peterson \& Swanson, 1964); hypoglycaemia (Rigg \& Bercu, 1967); drug intoxication (Richet, de Novales \& Verroust, 1970) and hypertensive crises. A considerable proportion remain unexplained however, and in the present series a specific cause was elicited in only one case-a hypertensive crisis due to toxaemia of pregnancy.

Tyler suggests that these confusional states occur particularly in individuals with pre-existing unstable personalities. This view was not supported by the histories of the patients in the present series. It was noticeable, however, that the florid nature of their symptomatology readily led to the assumption that they were severely, chronically emotionally unstable. This is a matter of considerable importance as such a view may prejudice their chances of being accepted for exacting treatments, especially long-term haemodialysis.

(3) Language and cultural difficulties are particularly important in acutely ill patients, in whom intense anxiety may be created if they feel unable to communicate their needs and uncertainties. This is particularly so if some degree of clouding of consciousness is present. Frightening misinterpretations then easily build up uncorrected. Amongst misinterpreted incidents that provoked intense anxiety in this series were unexpected moves back to intensive care facilities or to wards associated with an earlier stage of treatment, unexpected blood transfusions, intense scrutiny of monitoring equipment by staff, and nudity in the intensive care unit.

(4) Follow-up is particularly important in patients with somatic symptoms suspected to be psychogenic.
As will be discussed, diagnosis is tentative in many such patients and it is essential that this be frankly recognized, rather than the patients being fitted prematurely into a functional or organic niche.

\section{Attempted suicide}

Cases of attempted suicide, or self-poisoning, constituted numerically the single most important group of referrals.

There was little to distinguish this group from other reported series of attempted suicide (Stengel, 1964; Kessel, 1965; Stanley, 1969). Typically, age and sex distribution showed a predominance of females and a concentration amongst the 20-40 age group whilst personality disorders and depression share $\$$ the bulk of the diagnoses. Table 4 shows the diag noses in more detail. In each case, in addition to the primary diagnosis, other factors are tabulated personality disorder, depression and social crises, which, whilst not sufficiently important to form the primary diagnosis, were relevant to the suicidal attempt and illustrate the complexity of the motivating circumstances.

Table 5 shows the method of poisoning used. An unusual finding is the very extensive use of antidepressant drugs and the newer tranquillizers. It seems that these may be overtaking the more traditional barbiturates in popularity. Kessel (1965) commented on the rising importance of these psychotropic drugs, although in his series they still formed

TABLE 5. Methods of attempted suicide

\begin{tabular}{lrr}
\hline Method & No. & $\%$ \\
\hline Psychotropic drugs & 30 & 28 \\
Barbiturate hypnotics & 29 & 27 \\
Non-barbiturate hypnotics & 13 & 12 \\
Aspirin/paracetamol & 13 & 12 \\
Coal gas & 5 & 4 \\
Anticonvulsants & 4 & 3 \\
Other & 15 & 14 \\
$\quad$ Total & 109 & 100 \\
\hline
\end{tabular}

Drugs from one group used in sixty-one attempts, two in twenty-one attempts and three in two_attempts. 
only $23 \%$ of the methods used, whilst barbiturates constituted $55 \%$. The present findings emphasize the aptness of his remark that "change in fashion is so rapid that it is difficult to develop correct routines of medical management'.

Stanley (1969) has pointed out how unsatisfactory the treatment of many of the patients in his series proved to be- $28 \%$ either refused treatment or discharged themselves from it within a few days. In the present series, $29 \%$ of the total behaved similarly. Nineteen of the patients offered out-patient treatment did not attend appointments, or stopped prematurely, whilst four had refused treatment whilst in the ward. Additional patients may have discharged themselves prematurely from the hospitals to which they were referred.

On the other hand, a small proportion of patients were particularly rewarding to treat-they had suffered severe depression over considerable periods and once the self-poisoning led to this being recognized, responded well to treatment.

\section{Discussion and conclusions}

This survey of psychiatric consultations in a technologically advanced postgraduate teaching hospital illustrates some aspects of general hospital psychiatry which tend to be neglected in the literature.

The complexity of some of the diagnostic problems encountered was consonant with the highly specialized nature of some of the medical and surgical procedures undertaken. However, such problems are likely to become more general with the increasing development and dissemination of such complex techniques. Amongst the main diagnostic groups differentiated the organic reactions are particularly noteworthy. Their practical importance is evident-diagnosis is often different for reasons which have been outlined, yet incorrect diagnosis may lead to serious mismanagement, to disability or even to death, whilst an ageing population and the introduction of new drugs and techniques are likely to increase their frequency. Despite this they seem to fail to excite the interest of either physician or psychiatrist, though admirably suited to form a bridge between the two. Lipowski (1967) has suggested delirium as a model of psychosomatic disorder, but attention tends to concentrate on the classical psychosomatic disorders, referral of which appears in fact to be surprisingly uncommon. More commonly referred in the present series were patients with localized somatic symptoms suspected of being psychogenic. These are a well recognized and widespread problem but there may be special pressures to attempt a clear-cut and final diagnosis when advanced diagnostic techniques are readily available. It may be necessary to resist such pressures and insist on the careful follow-up and reassessment from an unbiased position which is likely to lead eventually to a more reliable diagnosis. The mere detection of organic pathology does not establish its aetiological importance; nor does the finding of psychopathology: cervical spondylosis and hiatus hernia have their psychiatric equivalents.

Numerically, the most important groups of referrals were the affective disorders and attempted suicides. The two main sets of precipitants of affective disorder differentiated, 'social' and 'illness' have been described, and the somewhat different problems they posed. Despite the feasibility of this differentiation, complex interactions between social, physical and psychological factors inevitably occurred and a simplistic view of depression (Miller, 1967) received no support from this material.

The suicide attempts showed a similar complexity of aetiological factors, and the importance of social precipitants in both groups emphasizes the range of interest and activity-including liaison with community social agencies-required of the psychiatrist in even the most technologically oriented centres.

The management problems set by suicide attempters have been described. These are universal, although in the present setting failure shows up particularly badly. A coherent and successful policy for dealing with these problems might do a great deal to improve the acceptance of psychiatrists in the general hospital.

\section{Acknowledgment}

I am grateful to Dr A. W. Lishman for much helpful advice and criticism.

\section{References}

ABrahamson, D. (1971) Psychological effects of open heart surgery. M.D Thesis, University of Dublin. (In preparation.)

Alexander, C.S., \& Nino, A. (1969) Cardiovascular complications in young patients taking psychotropic drugs. American Heart Journal, 78, 757.

AndRew, J. \& Nathan, P.W. (1964) Lesions of the anterior frontal lobes and disturbances of micturition and defaecation. Brain, 87, 233.

BAIRD, D. (1969) Combined Textbook of Obstetrics and Gynaecology, pp. 858-83. E. \& S. Livingstone, London.

Brook, C.P.B. \& Stafford-Clark, D. (1961) Psychiatric treatment in general wards. Lancet, i, 1159.

CRISP, A.H. (1968) The role of the psychiatrist in the general hospital. Postgraduate Medical Journal, 44, 267.

Culpan, R. \& Davis, B. (1960) Psychiatric illness at medical and surgical outpatient clinics. Comprehensive Psychiatry, 1, 228 .

Denney, D., Quass, R.M. \& RICH, D.C. (1966) Psychiatric patients on medical wards. Archives of General Psychiatry, 14, 530.

Department of Health and Social Security (1970) The Future Structure of the National Health Service. H.M.S.O., London.

EILENBERG, M.D. (1965) Survey of inpatient referrals to an American psychiatric department. British Journal of Psychiatry, 111, 1211. 
ENGEL, G.L. (1967) Medical Education and the psychosomatic approach. Journal of Psychosomatic Research, 11, 77.

Fleminger, J.J. \& Mallett, B.L. (1962) Psychiatric referrals from medical and surgical wards. Journal of Mental Science, 108, 183.

Helsborg, H.C. (1958) Psychiatric investigations of patients in a medical department. Acta Psychiatrica Scandinavica, 33, 303.

HockadAY, W.J. (1961) Experiences of a psychiatrist as a member of a surgical faculty. American Journal of Psychiatry. 117, 706.

Hoenig, J. \& Hamilton, M.W. (1969) The Desegregation of the Mentally Ill. Routledge \& Kegan Paul, London.

Holmes, J. McD. (1956) Cerebral manifestations of vitamin $\mathrm{B}_{12}$ deficiency. British Medical Journal, 2, 1394.

Hunter, R., Blackwood, W. \& Bull, J. (1968) Three cases of frontal meningiomas presenting psychiatrically. British Medical Journal, 3, 916.

KEMPH, J.P. (1969) Psychiatry and new surgical proceduresa challenge to the profession. American Journal of Psychiatry, 126, 396.

Kennedy, A.C., Linton, A.L. \& Eaton, J.C. (1962) Urea levels in cerebrospinal fluid after haemodialysis. Lancet, $i$, 410.

KenYoN, F.E. \& RutTer, M.L. (1963) The psychiatrist and the general hospital. Comprehensive Psychiatry, 4, 80.

KeSSEL, W.I.N. (1965) Self-poisoning. British Medical Journal, 2, 1265.

KoRnFeld, D.S. \& Feldman, M. (1965) The psychiatric service in the general hospital. New York State Journal of Medicine, 65, 1332.

LIPOWSKI, Z.J. (1967a) Review of consultation psychiatry and psychosomatic medicine. I. General principles. Psychosomatic Medicine, 29, 153.

LIPOWSKI, Z.J. (1967b) Review of consultation psychiatry and psychosomatic medicine. II. Clinical aspects. Psychosomatic Medicine, 29, 201.

Mechanic, D. \& VolkaRT, E.H. (1961) Stress, illness behaviour and the sick role. American Sociological Review, 26, 51 .

Miller, H. (1967) Depression. British Medical Journal, 1, 257.

Mindham, R.H.S. (1970) Psychiatric symptoms in Parkinsonism. Journal of Neurology, Neurosurgery and Psychiatry, 33, 188.

Peterson, H. \& Swanson, A.G. (1964) Acute encephalopathy occurring during haemodialysis. Archives of Internal Medicine, 113, 877.

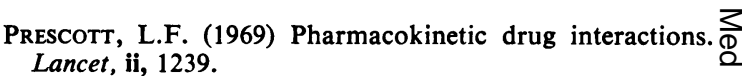

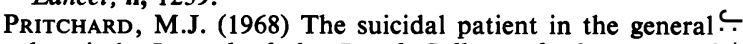
hospital. Journal of the Royal College of Physicians of London, 2, 422.

QUERIDO, A. (1959) Forecast and follow-up: an investigation into the clinical, social and mental factors determining the $\frac{\bar{\sigma}}{\sigma}$ results of hospital treatment. British Journal of Preventive $\overline{\bar{\omega}}$. and Social Medicine, 13, 33.

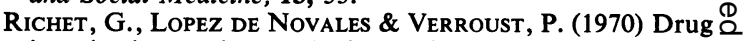
intoxication and neurological episodes in chronic renal failure. British Medical Journal, 1, 394.

Richman, A., Slade, H.C. \& Gordon, G. (1966) Symptom $\vec{\circ}$ questionnaire reliability in assessing the need for psychia- tric care. British Journal of Psychiatry, 112, 549.

RigG, G.A. \& BERCU, B.A. (1967) Hypoglycaemia-a complication of haemodialysis. New England Journal of Medi-응 cine, 277, 1139.

Ross Russell, R.W. \& Pennybacker, J. (1961) Craniopharyngioma in the elderly. Journal of Neurology, Neuro- $\underset{V}{ }$ surgery and Psychiatry, 24, 1.

ROTH, M. \& MYers, D.H. (1969) The diagnosis of dementia. of British Journal of Hospital Medicine, 2, 703.

SHEPHERD, M., LADER, M. \& RODNIGHT, R. (1968) Clinical ô Psychopharmacology, p. 140. The English Universities Press, London.

Shulman, R. (1967) Vitamin $\mathbf{B}_{12}$ deficiency and psychiatric illness. British Journal of Psychiatry, 113, 252.

Silverman, M. (1961) A comprehensive department of $\frac{\mathbb{D}}{O}$ psychological medicine. British Medical Journal, 2, 698.

SMITH, A.D.M. (1960) Megaloblastic madness. Britist Medical Journal, 2, 1840.

Stanley, W.J. (1969) Attempted suicide and suicidal ges tures. British Journal of Preventive and Social Medicine, 190.

Stenger, E. (1964) Suicide and Attempted Suicide, pp. 22-26 Penguin Books, London.

Strachan, R.W. \& Henderson, J.G. (1965) Psychiatric syndromes due to avitaminosis $\mathrm{B}_{12}$ with normal blood and marrow. Quarterly Journal of Medicine, 34, 303.

TyLER, H.R. (1968) Neurologic disorders in renal failure. American Journal of Medicine, 44, 734.

WATSON, J.P., BenNeTt, D.H. \& IsAaCs, A.D. (1970) Psychiatric units in general hospitals. Lancet, i, 511.

Zwerling, I., Titchener, J., GotTSChalK, L., Levine, M., Cuthbertson, W., Cohen, J.F. \& Silver, H. (1955) Personality disorder and the relationship of emotion to surgical illness in 200 surgical patients. American Journal of Psychiatry, 112, 270. 